Research Article

\title{
Stress Corrosion Cracking of a Forged Mg-Al-Zn Alloy with Different Surface Conditions
}

\author{
Zhongwei Yin, Fengjuan Liu ${ }^{D}$, Dongdong Song, Shihuan He, Jun Lin, and Feng Yu
}

Aerospace Research Institute of Materials and Processing Technology, Beijing 100076, China

Correspondence should be addressed to Fengjuan Liu; 358127326@qq.com

Received 25 October 2017; Revised 2 March 2018; Accepted 23 April 2018; Published 14 May 2018

Academic Editor: Mohamed Azaroual

Copyright (C) 2018 Zhongwei Yin et al. This is an open access article distributed under the Creative Commons Attribution License, which permits unrestricted use, distribution, and reproduction in any medium, provided the original work is properly cited.

\begin{abstract}
Stress corrosion cracking (SCC) of a forged Mg-Al-Zn magnesium alloy with different surface conditions was studied by the fourpoint bending test and alternate immersion test in $\mathrm{NaCl}$ solution. The results showed that the bare $\mathrm{Mg}$ - $\mathrm{Al}-\mathrm{Zn}$ magnesium alloy has low susceptivity to SCC, and no abrupt rupture happened after the immersion test for 5 days under an initial stress load of $0.15-0.75 \sigma_{0.2}$. With microarc oxidation (MAO) coating, corrosion resistance was enhanced, but more surface cracks were induced, and microcracks could be detected inside corrosive pits when the load was $0.75 \sigma_{0.2}$, which is similar to the bare alloy. The composite coating totally avoided both SCC and corrosion. The low susceptivity of the forged AQ80M alloy to SCC should be attributed to the fine grain size and even distribution of secondary phases around the grain boundary.
\end{abstract}

\section{Introduction}

Magnesium alloys are competitive as light-weight structure materials in the industrial applications due to their suitable mechanical properties and high strength to weight ratios [1]. Among the various commercial magnesium alloys, the developed $\mathrm{AZ}$ series of $\mathrm{Mg}$ alloys $(\mathrm{Mg}-\mathrm{Al}-\mathrm{Zn})$ have found the largest number of industrial applications [2], such as automotive and aerospace parts, electronic devices, and weapons. Recently, the AZ80 alloy has attracted more attention for its high strength and low price [3]. With a little bit of Ag addition into the AZ80 alloy, the obtained new AQ80M alloy exhibits much higher high-temperature mechanical properties, which is desirable in the aerospace parts [4].

However, besides the poor resistance of common $\mathrm{Mg}$ alloys to corrosion [5-14], the high susceptivity of AZ serials of $\mathrm{Mg}$ alloys to stress corrosion cracking (SCC) [15-23] is also a limit for further service applications. It is reported that SCC of Mg-Al alloys occurs even in distilled water [14]. The SCC behavior of AZ31 and AZ91 alloys in various environments has been reported in the literatures [24-28]. However, relatively very few work is found on the AZ80 alloy [29], and even less on AQ80M. Furthermore, as structure parts, Mg alloys are usually treated with different protective coatings. With different surface states, the stress corrosion behavior of AQ80M is still unclear.

Therefore, the present study aimed at investigating the stress corrosion activity of the AQ80M magnesium alloy with bare metal and different surface states in sodium chloride solution.

\section{Experimental Methods}

2.1. Materials and Specimens. The substrate material used for this investigation was a forged AQ80M $\mathrm{Mg}$ alloy with a chemical composition (in wt. \%) of $8.5 \% \mathrm{Al}, 0.5 \% \mathrm{Zn}, 0.2 \%$ $\mathrm{Mn}, 1 \% \mathrm{Ag}, 0.1 \% \mathrm{Si}, 0.01 \% \mathrm{Cu}, 0.005 \% \mathrm{Ni}, 0.003 \% \mathrm{Fe}$, and balance $\mathrm{Mg}$. All samples for the stress corrosion test were cut into a size of $20 \mathrm{~mm} \times 140 \mathrm{~mm} \times 4 \mathrm{~mm}$.

The electrolyte for microarc oxidation (MAO) is composed of $\mathrm{Na}_{2} \mathrm{SiO}_{3}, \mathrm{KOH}, \mathrm{Na}_{2} \mathrm{HPO}_{3}$, and $\mathrm{C}_{3} \mathrm{H}_{8} \mathrm{O}_{3}$. The sealant and primer are of epoxy resin, and the topcoat is polyurethane. For the MAO process, the AQ80 Mg alloy samples were used as the anode, and the temperature of electrolyte solution was below $45^{\circ} \mathrm{C}$ during MAO treatment. The MAO coating was applied with a fixed voltage of $320 \mathrm{~V}$ at $600 \mathrm{~Hz}$ for $10 \mathrm{~min}$ using a $200 \mathrm{~kW}$ AC power supply with a duty cycle of $40 \%$. The organic sealant and top coatings 


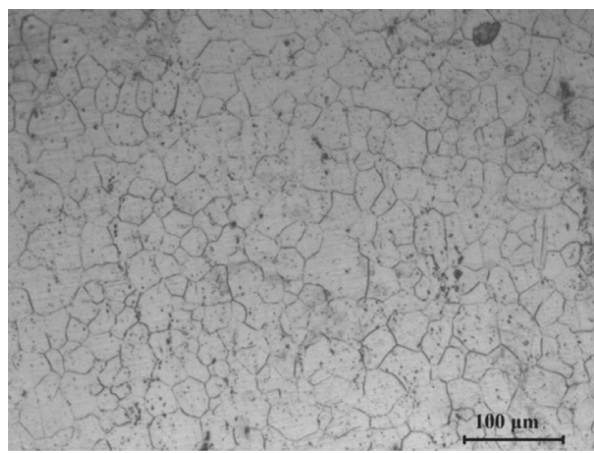

(a)

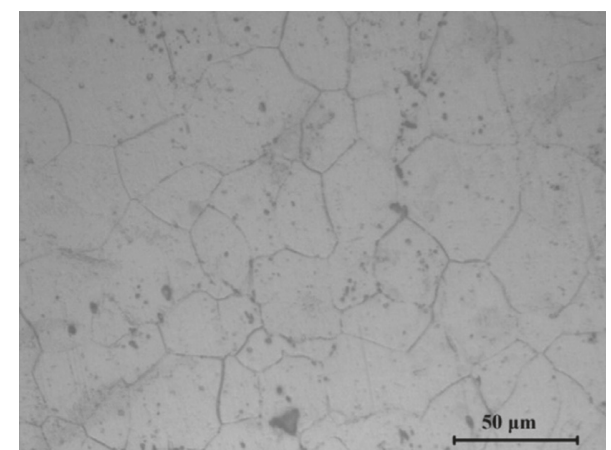

(b)

Figure 1: Microstructures of the AQ80M alloy with different magnifications.

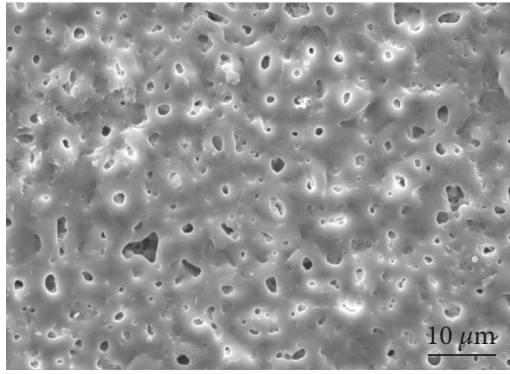

(a)

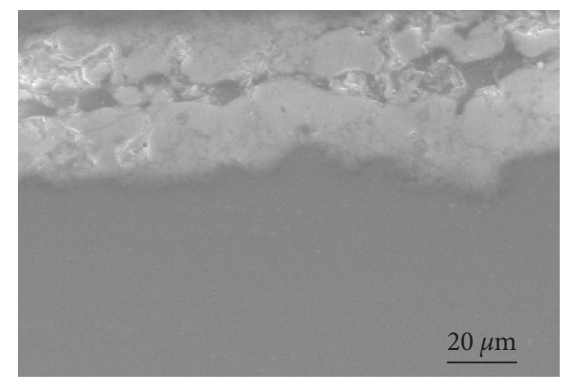

(b)

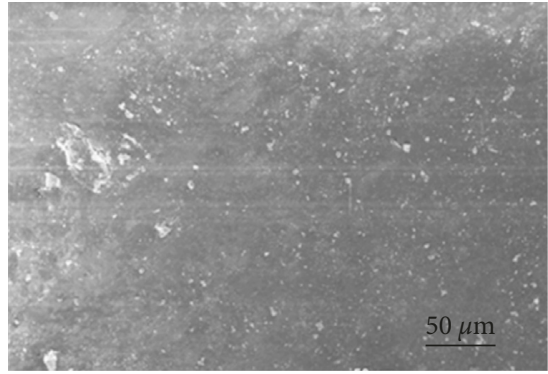

(c)

Figure 2: (a) MAO surface morphology, (b) cross sections of MAO, and (c) multiple coating surface.

were applied by spray gun with an aperture of $1.3 \mathrm{~mm}$ in diameter and $0.4-0.6 \mathrm{MPa}$ pressure. The viscosity is controlled between $18 \sim 60 \mathrm{~s}$ with Tu-4 Cup according to the specific request of the lacquer.

The SCC test is carried in an 3.5\% (wt) sodium chloride solution at room temperature, and the $\mathrm{pH}$ value of solution is 6.4-7.2. In the alternate immersion trial chest, the specimens are immersed in the solution for $10 \mathrm{~min}$, and then exposed into the air for $50 \mathrm{~min}$ per hour, and the total test time is $120 \mathrm{~h} \sim 480 \mathrm{~h}$.

2.2. Characterization and Testing. The stress corrosion test is carried on through the four-point bending test according to the standard GB/T 15970.2-2000, which is loaded by constant strain means. With yield strength of $210 \mathrm{MPa}$, elastic model of $43 \mathrm{GPa}$, and outside and inside pivot distance of $115 \mathrm{~mm}$ and $57 \mathrm{~mm}$, respectively, the calculated flexibility corresponds to the initial loading stress, which is 0.15 0.75 times of yield strength.

Electrochemical impedance spectroscopy (EIS) was employed to compare the corrodibility of the AQ80M alloy with its pure metal surface, MAO coating, and finished coating. The optical microscope is used to study the metallographic structure of the AQ80M Mg alloy. Scanning electron microscope (SEM) and laser scanning confocal microscope (LSCM) were adopted to analyze the specimens for better understanding of the obtained results.

\section{Results and Discussion}

3.1. Microstructure and Coatings Characteristics. The microstructures of the AQ80M alloy observed under different magnifications are given in Figure 1. The alloy consisted mainly of $\alpha-\mathrm{Mg}$ grains agglomerated with the secondary $\beta$ phase $\left(\mathrm{Mg}_{24} \mathrm{Al}_{17}\right)$. The average grain size of the base phase is less than $50 \mu \mathrm{m}$, and the black and tiny secondary phases are distributed evenly around the grain boundary. The addition of Ag could improve the precipitation hardening of the $\beta$ phase but could not be observed on the optical micrograph.

Figure 2 shows the SEM images of surface and cross section of MAO layers formed on the AQ80M alloy and the surface of MAO-sealing-primer-top coating layers (multiple coating). The MAO coating is about $16 \mu \mathrm{m}$ thick, and its surface is covered with abundant microholes with a diameter of about $3 \mu \mathrm{m}$ in average. With four layers of coatings including MAO, the multiple coating is about $80 \sim 100 \mu \mathrm{m}$ thick, and the sealing particles could be found in the microholes of MAO coating.

To understand better the anticorrosion performance of the AQ80M alloy with different surface conditions, which cannot be visualized, electrochemical tests were performed. Figures 3 and 4 display the results of the electrochemical tests. Figures 3 and 4 are the Bode and Nyquist plots of the EIS spectra, respectively for the coatings.

The circuit model as shown in Figure 5 was used to fit the impedance of MAO coating and multiple coating. In the 


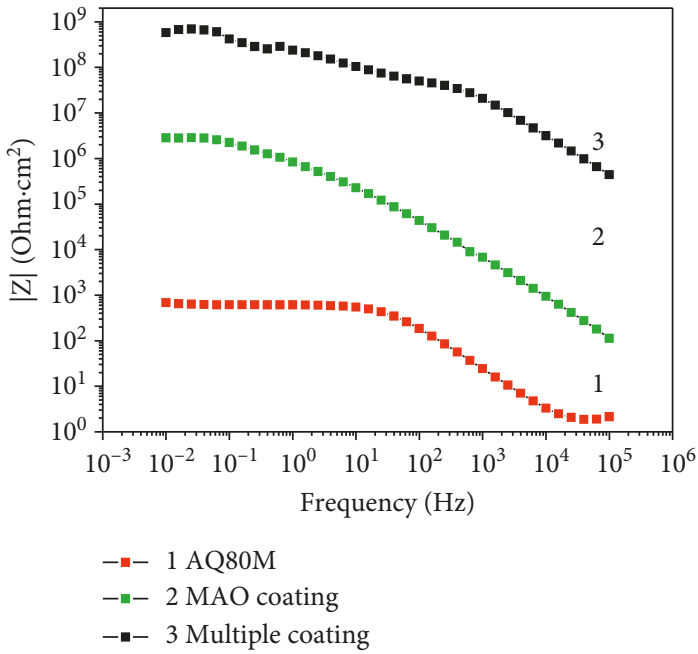

(a)

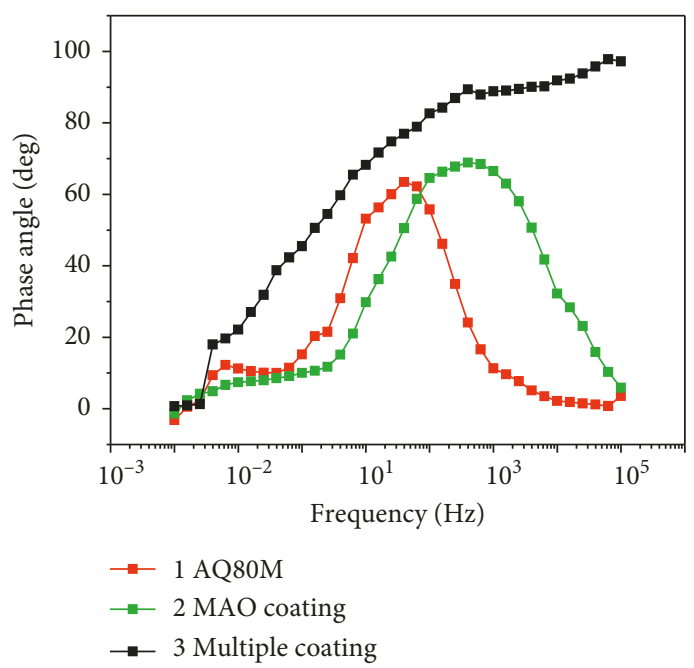

(b)

FIGURE 3: EIS results of the uncoated AQ80M Mg alloy, MAO coating, and multiple coating.

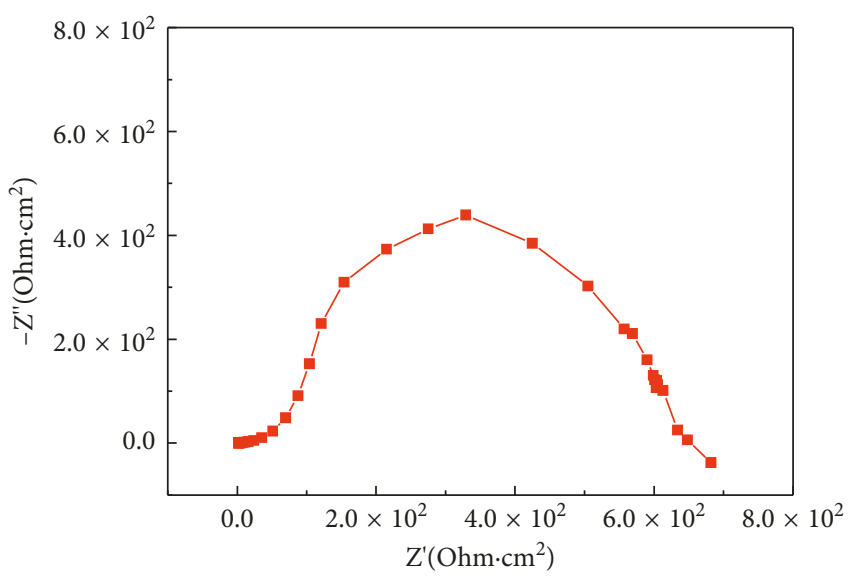

(a)

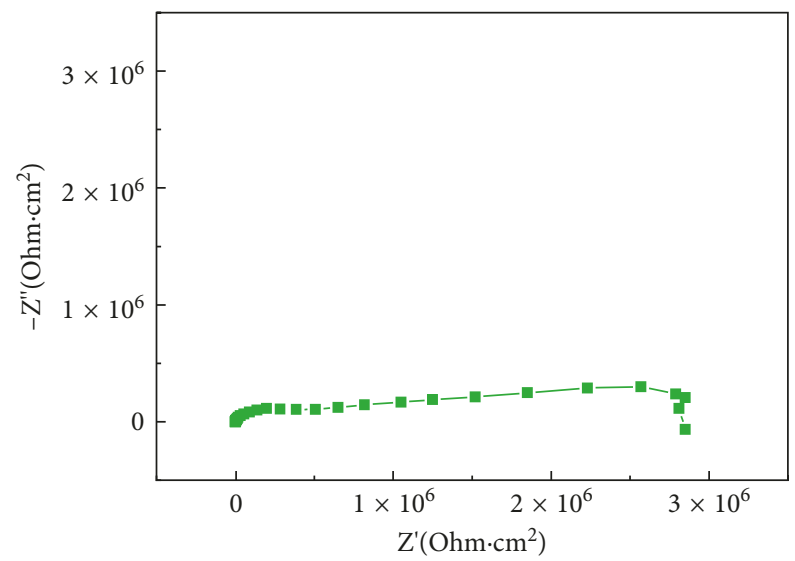

(b)

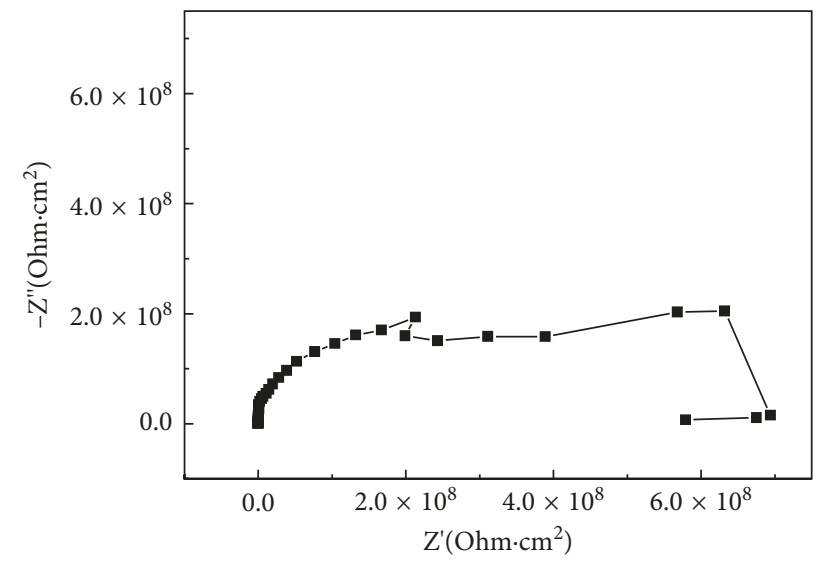

(c)

FIgURE 4: Nyquist plots of the three coatings: (a) AQ80M, (b) MAO coating, and (c) multiple coating.

circuits, $R_{\mathrm{s}}$ represents the resistance between the working electrode and reference electrode. $Q_{c}$ is related to the capacitance of the coating. $R_{\mathrm{c}}$ is the resistance of the pores and is a measure of the porosity as a consequence of the degradation of the coating. And $R_{\mathrm{c}}$ of MAO coating and multiple coating is $2.320 \times 10^{6}$ and $5.625 \times 10^{8}$, respectively. 


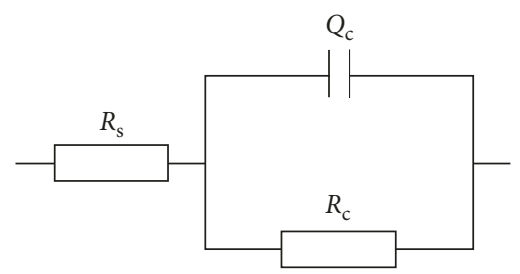

Figure 5: Circuit models for fitting the impedance of the coatings.
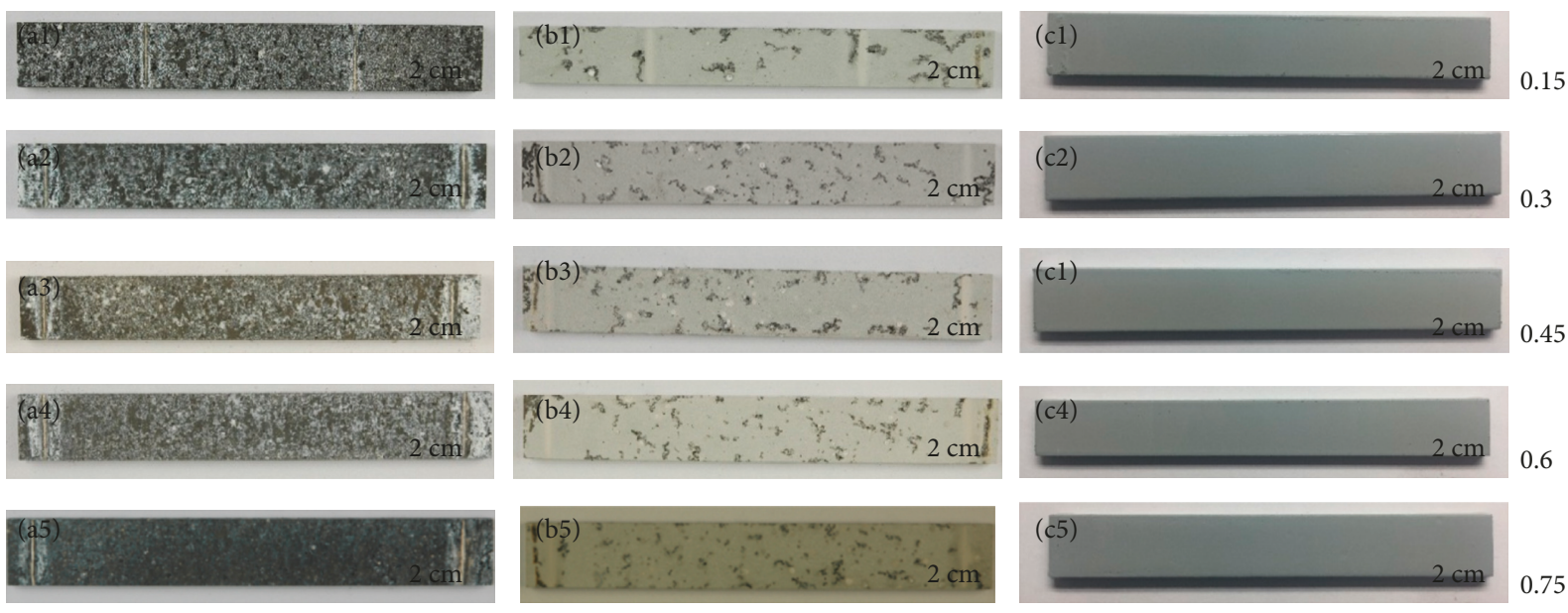

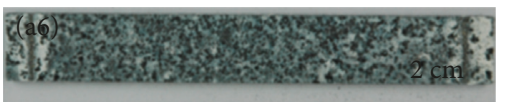

a1 a6: bare Mg alloy

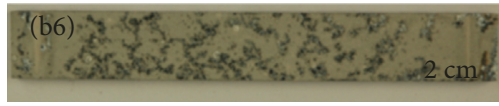

b1 b6: with MAO coating c1 c5: with multiple coating

FIgURE 6: Digital macroscopic pictures of the AQ80M Mg alloys with different conditions: a1 a6: bare Mg alloy, b1 b6: with MAO coating, and $\mathrm{c} 1 \sim \mathrm{c} 5$ : with multiple coating.

Multiple coating improves the anticorrosion performance significantly.

3.2. Stress Corrosion Test Results. With an initial load of $0.15 \sim 0.75$ times of yield strength $\left(\sigma_{0.2}\right)$, the specimens with bare, MAO, multiple coatings, respectively, are alternately immersed in the $\mathrm{NaCl}$ solution for the SCC tests. Figure 6 shows the digital macroscopic pictures of the AQ80M Mg alloys, and $\mathrm{a} 1 \sim \mathrm{a} 6, \mathrm{~b} 1 \sim \mathrm{b} 6$, and $\mathrm{c} 1 \sim \mathrm{c} 5$ correspond to bare, $\mathrm{MAO}$, and multiple coatings, respectively. Besides, Figures a1 a5, b1 b5, and $c 1 \sim c 5$ are taken with specimens tested under an initial load of $0.15-0.75 \sigma_{0.2}$, respectively. The test time is $120 \mathrm{~h}$ for $\mathrm{a} 1 \sim \mathrm{a} 5$ and $\mathrm{b} 1 \sim \mathrm{b} 5$ and is $480 \mathrm{~h}$ for $\mathrm{c} 1 \sim \mathrm{c} 5$. The specimens a6 and b6 are loaded with $0.75 \sigma_{0.2}$ and tested for $240 \mathrm{~h}$.

It is obvious that the bare $\mathrm{Mg}$ alloy specimens (Figure $6(\mathrm{a} 1 \sim \mathrm{a} 6))$ took place in general and even severe corrosion for the abundance of small corrosive pits. And the corrosive pits size does not change distinctly with different loads; however, it becomes much bigger when the test time is $240 \mathrm{~h}$ instead of $120 \mathrm{~h}$ for Figure 6(a6). No obvious cracks could be found on all specimens by eye observation.

Although the MAO coating was locally destroyed, the specimens erode much slightly than the bare metal. This illustrates that the MAO coating is effective to enhance the corrosion resistance of the $\mathrm{Mg}$ alloy. The corrosion degree varies similarly as that of bare metal; that is, there is no obvious difference between different loaded specimens, and specimen B6 exhibits more severe corrosion. No obvious cracks could be found on all MAO coating surfaces by eye observation.

For the specimens with multiple coating, there is no obvious corrosion which could be found for all samples tested for $480 \mathrm{~h}$. It seems that present protective coating totally prevents the specimens from corrosion and further stress corrosion, in the condition of loading as high as 0.75 times of yield strength.

With stress of $0.15 \sim 0.75$ times of tensile yield strength, no abrupt rupture happened after the alternate immersion test for 5 days. Figure 7 shows the SEM micrographs of the AQ80M bare alloys with different initial stress. Figures $7(\mathrm{a})-7(\mathrm{~d})$ are the representative pictures of corrosive pits (red arrows) with a load of $0.3-0.75 \sigma_{0.2}$ and tested for $120 \mathrm{~h}$, and Figure $7(\mathrm{e})$ is tested for $240 \mathrm{~h}$ under a load of $0.75 \sigma_{0.2}$. From the figures, we could find that there are no cracks on Figures $7(\mathrm{a})-7(\mathrm{c})$, although too many corrosive pits have joint together. However, microcracks could be found inside the corrosive pits on Figure 7(d), and similar cracks could also be detected both inside and between the corrosive pits 


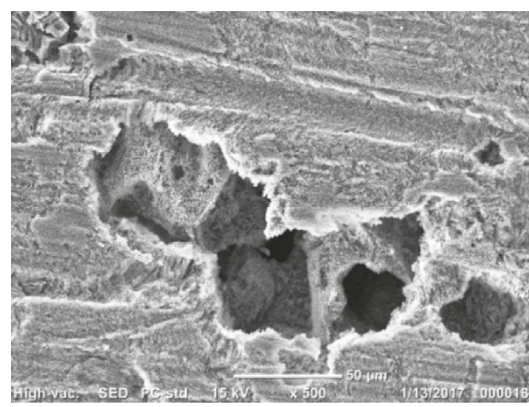

(a)

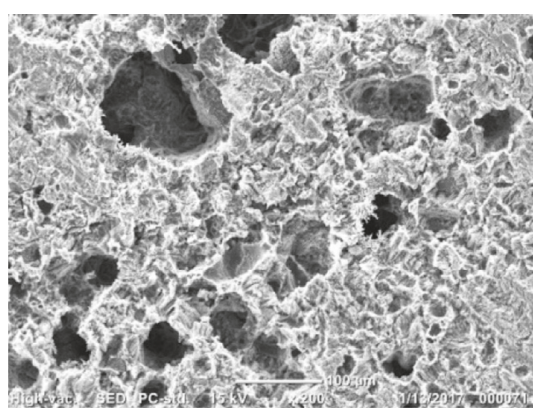

(c)

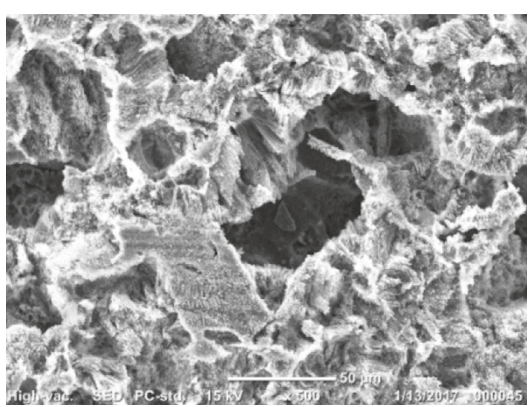

(b)

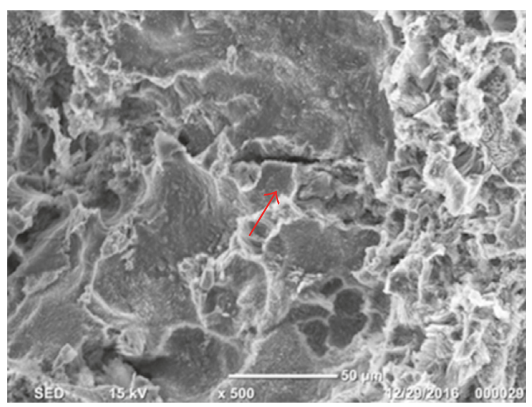

(d)

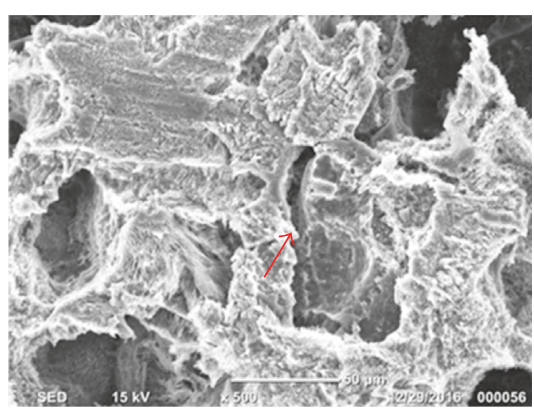

(e)

FIGURE 7: SEM micrographs of the AQ80M bare alloy with different strains: (a) $0.3 \sigma_{0.2} \times 120 \mathrm{~h}$, (b) $0.45 \sigma_{0.2} \times 120 \mathrm{~h},\left(\right.$ c) $0.6 \sigma_{0.2} \times 120 \mathrm{~h}$, (d) $0.75 \sigma_{0.2} \times 120 \mathrm{~h}$, and (e) $0.75 \sigma_{0.2} \times 240 \mathrm{~h}$.

on Figure $7(\mathrm{e})$, which is tested for more times with a load of $0.75 \sigma_{0.2}$. This illustrated that $0.75 \sigma_{0.2}$ is close to the stress threshold value for the present AQ80M alloy.

The low susceptivity of the forged AQ80M alloy to SCC should be attributed to the fine grain size and even distribution of secondary phases around the grain boundary (Figure 1). The microcracking initiated from the surface pitting, and virtual stress increased with the progress of pitting corrosion.

Figure 8 shows the SEM micrographs of the AQ80M alloys with MAO coating under different initial stress. Figures $8(\mathrm{a})-8(\mathrm{e})$ are the representative pictures of the specimen surface after testing for $120 \mathrm{~h}$ with a load of $0.3 \sim 0.75 \sigma_{0.2}$, and Figure $8(\mathrm{f})$ is tested for $240 \mathrm{~h}$ under a load of $0.75 \sigma_{0.2}$. Compared with the bare alloy, low-grade corrosion takes place on the MAO coating surfaces, and less corrosive pits could be observed. However, obvious macroscopic cracks (red arrows) could be found on the MAO coating surfaces in Figures $8(\mathrm{~b})-8(\mathrm{~d})$ with a load of $0.45 \sim 0.75 \sigma_{0.2}$, and no microcracks could be found inside the corrosive pits (Figure 8(e)), although the MAO coating was destroyed and serious corrosion took place here. These macroscopic cracks might originate from the MAO process or form on the MAO coating surface during loading for the brittle ceramic nature of coating materials. Comparing Figures $8(\mathrm{e})$ and $8(\mathrm{f})$, after testing for $240 \mathrm{~h}$ with a load of $0.75 \sigma_{0.2}$, similar destroy of MAO coating and serious corrosion at the destroyed place occurred on the surface of Figure 8(f), whereas the surface cracks decreased and microcracks could be observed inside the corrosive pits. This might be attributed to higher corrosive rate of the $\mathrm{Mg}$ alloy than the formation rate of surface cracks, and the surface cracks are eroded.

Figure 9 shows the LSCM micrographs of AQ80M alloys with multiple coating under different initial stress tested for $480 \mathrm{~h}$. The multiple coatings are all intact and undestroyed, and no corrosion or any microcracks could be detected on all surfaces. With such effective protection, the under layer metals are supposed to be not corrosive and cracked. Therefore, the composite coating improved the corrosion resistance distinctly, and also the SCC was totally avoided. 


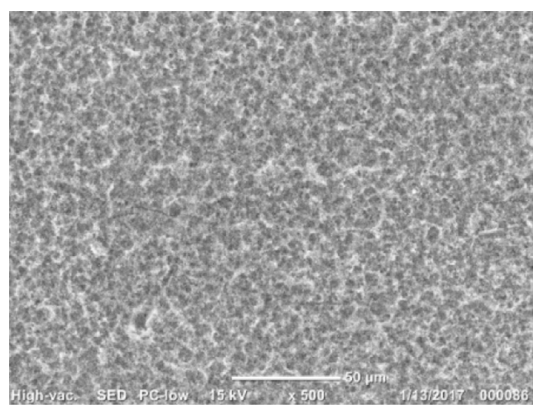

(a)

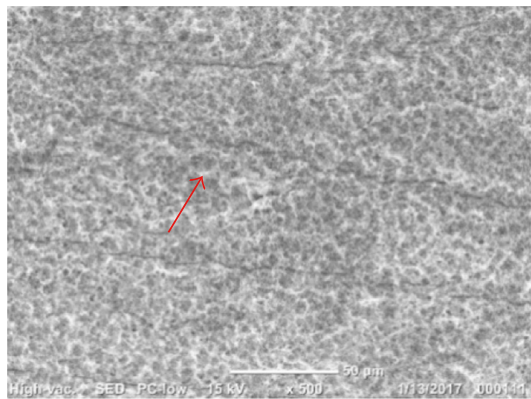

(c)

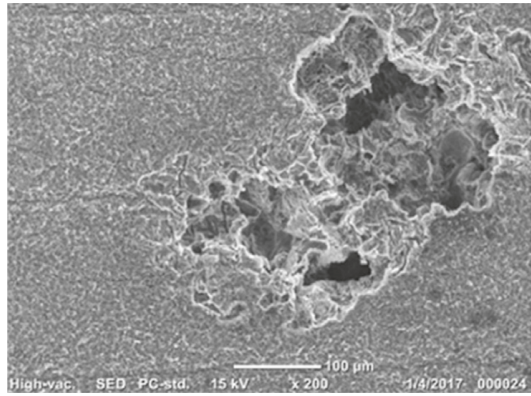

(e)

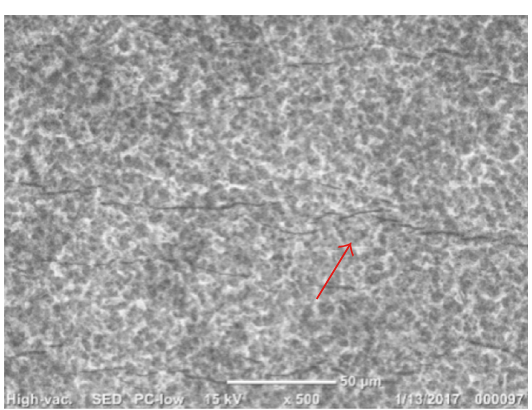

(b)

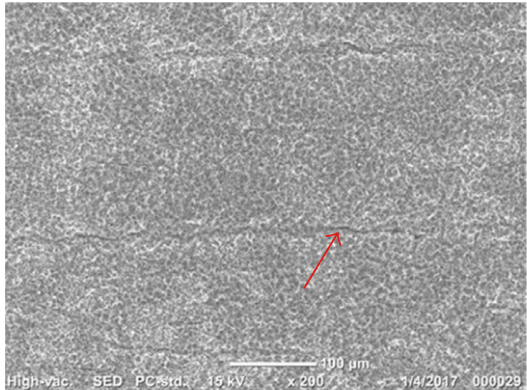

(d)

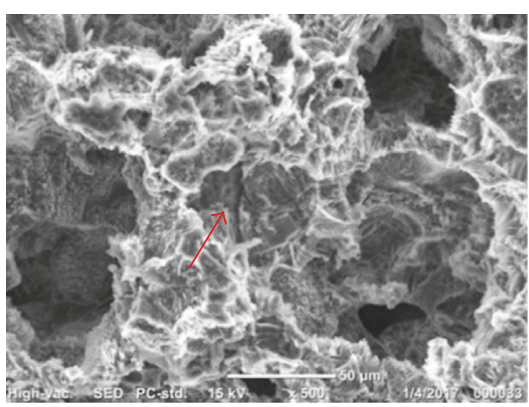

(f)

FIGURE 8: SEM micrographs of the AQ80M alloy with MAO coating under different strains: (a) $0.3 \sigma_{0.2} \times 120 \mathrm{~h},(\mathrm{~b}) 0.45 \sigma_{0.2} \times 120 \mathrm{~h}$, (c) $0.6 \sigma_{0.2} \times 120 \mathrm{~h},(\mathrm{~d}) 0.75 \sigma_{0.2} \times 120 \mathrm{~h}$, (e) $0.75 \sigma_{0.2} \times 120 \mathrm{~h}$, and (f) $0.75 \sigma_{0.2} \times 240 \mathrm{~h}$.
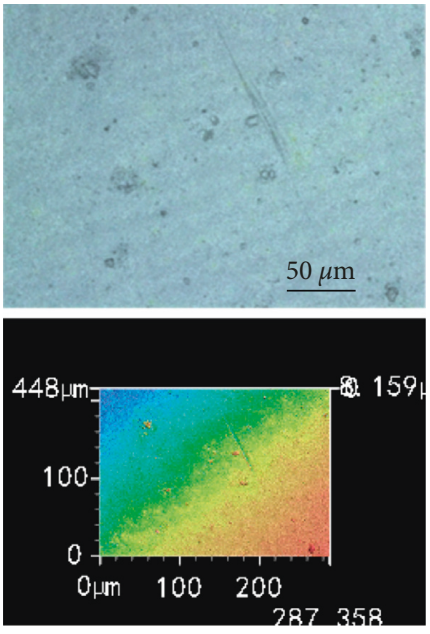

(a)
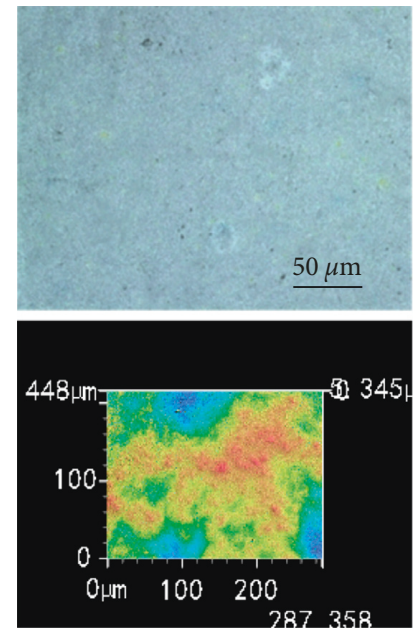

(b)
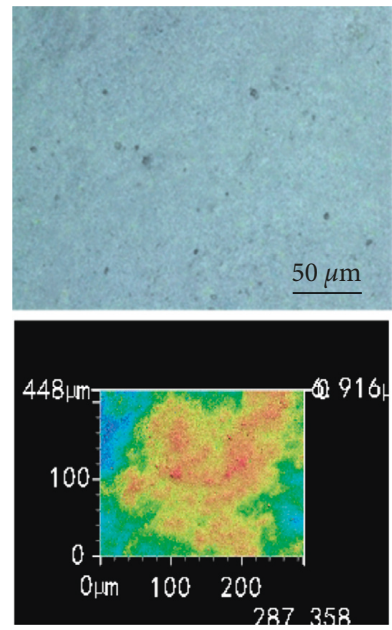

(c)
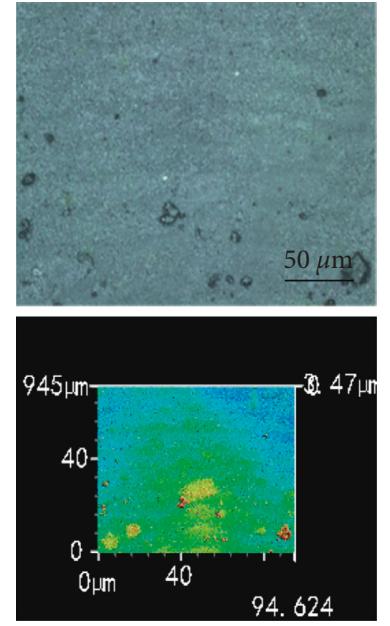

(d)

FIGURE 9: LSCM micrographs of the AQ80M alloy with multiple coatings under different strains: (a) $0.3 \sigma_{0.2} \times 480 \mathrm{~h},(\mathrm{~b}) 0.45 \sigma_{0.2} \times 480 \mathrm{~h}$, (c) $0.6 \sigma_{0.2} \times 480 \mathrm{~h}$, and (d) $0.75 \sigma_{0.2} \times 480 \mathrm{~h}$. 


\section{Conclusions}

In this study, we found that the Mg-Al-Zn (AQ80M) magnesium alloy has low susceptivity to SCC in present $\mathrm{NaCl}$ solution. No abrupt rupture happened after the alternate immersion test for 5 days under an initial stress load of $0.15 \sim 0.75 \sigma_{0.2}$. For the bare alloy, some microcracks inside the corrosive pits could be observed when the load is $0.75 \sigma_{0.2}$. For the alloy with MAO coating, more surface cracks are induced by the brittle ceramic coating, and microcracks could be detected when the load is $0.75 \sigma_{0.2}$ and tested for 10 days. The composite coating totally avoided SCC and corrosion. No microcracks could be observed with a load of $0.75 \sigma_{0.2}$ after the immersion test for 20 days. The low susceptivity of the forged AQ80M alloy to SCC should be attributed to the fine grain size and even distribution of secondary phases around the grain boundary. The microcracking initiated from the surface pitting, and virtual stress increased with the progress of pitting corrosion.

\section{Disclosure}

The authors would like to acknowledge the 6th International Conference on Magnesium, which recently presented this work as poster presentation.

\section{Conflicts of Interest}

The authors declare that they have no conflicts of interest.

\section{Acknowledgments}

This work was supported by the Advanced Research project of General Armament Department (no. 51312JQ03).

\section{References}

[1] T. Abbott, "Magnesium: industrial and research developments over the last 15 years," Corrosion, vol. 71, no. 2, pp. 120-127, 2014.

[2] E. G. Hali, Magnesium Alloys, Uh Lig's Corrosion Handbook, John Wiley \& Sons Inc., New York, NY, USA, 2000.

[3] P. C. Wang, C. C. Lin, T. Y. Huang et al., "Effects of 2 mass\% $\mathrm{Li}$ addition on the AZ80 Mg alloy," Materials Transactions, vol. 49, no. 5, pp. 913-917, 2008.

[4] Designation and Composition of Wrought Magnesium and Magnesium Alloys, GB/T 5153-2016, 2016.

[5] Z. Shi, F. Cao, G. L. Song, M. Liu, and A. Atrens, "Corrosion behavior in salt spray and in $3.5 \% \mathrm{NaCl}$ solution saturated with $\mathrm{Mg}(\mathrm{OH})_{2}$ of as-cast and solution heat-treated binary Mg-RE alloys: RE=Ce, La, Nd, Y, Gd," Corrosion Science, vol. 76, pp. 98-118, 2013.

[6] G. Song and A. Atrens, "Understanding magnesium corrosion -a frame work for improved alloy performance," Advanced Engineering Materials, vol. 5, no. 12, pp. 837-858, 2003.

[7] G. Song and A. Atrens, "Recent insights into the mechanism of magnesium corrosion and research suggestions," Advanced Engineering Materials, vol. 9, no. 3, pp. 177-183, 2007.

[8] G. L. Song and A. Atrens, "Corrosion mechanisms of magnesium alloys," Advanced Engineering Materials, vol. 1, no. 1, pp. 11-33, 1999.
[9] G. Song, S. Hapugoda, and D. St. John, "Degradation of the surface appearance of magnesium and its alloys in simulated atmospheric environments," Corrosion Science, vol. 49, no. 3, pp. 1245-1265, 2007.

[10] G. Song and D. St. John, "Corrosion of magnesium alloys in commercial engine coolants," Materials and Corrosion, vol. 56, no. 1, pp. 15-23, 2005.

[11] G. L. Song, "A dipping E-coating for Mg alloys," Progress in Organic Coatings, vol. 70, no. 4, pp. 252-258, 2011.

[12] B. S. Padekar, V. S. Raja, and R. K. S. Raman, "Stress corrosion cracking of a wrought $\mathrm{Mg}-\mathrm{Mn}$ alloy under plane strain and plane stress conditions," Engineering Fracture Mechanics, vol. 102, pp. 180-193, 2013.

[13] B. S. Padekar, R. K. Singh Raman, V. S. Raja, and L. Paul, "Stress corrosion cracking of a recent rare-earth containing magnesium alloy, EV31A, and a common Al- containing alloy, AZ91E," Corrosion Science, vol. 71, pp. 1-9, 2013.

[14] N. Winzer, A. Atrens, W. Dietzel, V. S. Raja, G. Song, and K. U. Kainer, "Characterisation of stress corrosion cracking (SCC) of Mg-Al alloys," Materials Science and Engineering: A, vol. 488, no. 1-2, pp. 339-351, 2008.

[15] N. Winzer, A. Atrens, W. Dietzel, G. Song, and K. U. Kainer, "Evaluation of the delayed hydride cracking mechanism for transgranular stress corrosion cracking of magnesium alloys," Materials Science and Engineering: A, vol. 466, no. 1-2, pp. 18-31, 2007.

[16] N. Winzer, A. Atrens, W. Dietzel, G. Song, and K. U. Kainer, "Comparison of the linearly increasing stress test and the constant extension rate test in the evaluation of transgranular stress corrosion cracking of magnesium," Materials Science and Engineering: A, vol. 472, no. 1-2, pp. 97-106, 2008.

[17] N. Winzer, A. Atrens, W. Dietzel, G. Song, and K. U. Kainer, "Fractography of stress corrosion cracking of $\mathrm{Mg}-\mathrm{Al}$ alloys," Metallurgical and Materials Transactions A, vol. 39, no. 5, pp. 1157-1173, 2008.

[18] N. Winzer, A. Atrens, W. Dietzel, G. L. Song, and K. U. Kainer, "Stress corrosion cracking (SCC) in Mg-Al alloys studied using compact specimens," Advanced Engineering Materials, vol. 10, no. 5, pp. 453-458, 2008.

[19] N. Winzer, A. Atrens, G. L. Song et al., "A critical review of the stress corrosion cracking (SCC) of magnesium alloys," Advanced Engineering Materials, vol. 7, no. 8, pp. 659-693, 2005.

[20] F. Cao, Z. Shi, G. L. Song, M. Liu, M. S. Dargusch, and A. Atrens, "Stress corrosion cracking of several solution heat-treated Mg-X alloys," Corrosion Science, vol. 96, pp. 121-132, 2015.

[21] F. Cao, Z. Shi, J. Hofstetter et al., "Corrosion of ultra-highpurity $\mathrm{Mg}$ in $3.5 \% \mathrm{NaCl}$ solution saturated with $\mathrm{Mg}(\mathrm{OH})_{2}$," Corrosion Science, vol. 75, pp. 78-99, 2013.

[22] F. Cao, Z. Shi, G. L. Song, M. Liu, and A. Atrens, "Corrosion behavior in salt spray and in $3.5 \% \mathrm{NaCl}$ solution saturated with $\mathrm{Mg}(\mathrm{OH}) 2$ of as-cast and solution heat- treated binary Mg-X alloys: $\mathrm{X}=\mathrm{Mn}, \mathrm{Sn}, \mathrm{Ca}, \mathrm{Zn}, \mathrm{Al}, \mathrm{Zr}, \mathrm{Si}, \mathrm{Sr}$," Corrosion Science, vol. 76, pp. 60-97, 2013.

[23] F. Cao, Z. Shi, G. L. Song, M. Liu, M. S. Dargusch, and A. Atrens, "Influence of hot rolling on the corrosion behavior of several Mg-X alloys," Corrosion Science, vol. 90, pp. 176-191, 2015.

[24] Y. Zhao, G. Wu, J. Jiang, H. M. Wong, K. W. K. Yeung, and P. K. Chu, "Improved corrosion resistance and cytocompatibility of magnesium alloy by two-stage cooling in thermal treatment," Corrosion Science, vol. 59, pp. 360-365, 2012.

[25] H. S. Kim, G. H. Kim, H. Kim, and W. J. Kim, "Enhanced corrosion resistance of high strength $\mathrm{Mg}-3 \mathrm{Al}-1 \mathrm{Zn}$ alloy sheets with ultrafine grains in a phosphate buffered saline solution," Corrosion Science, vol. 74, pp. 139-148, 2013. 
[26] Z. Wen, C. Wu, C. Dai, and F. Yang, "Corrosion behaviours of $\mathrm{Mg}$ and its alloys with different $\mathrm{Al}$ contents in a modified simulated body fluid," Journal of Alloys and Compounds, vol. 488, no. 1, pp. 392-399, 2009.

[27] Y. Xin, C. Liu, X. Zhang, G. Tang, X. Tian, and P. K. Chu, "Corrosion behaviour of biomedical AZ91 magnesium alloy in simulated body fluid," Journal of Materials Research, vol. 22, no. 7, pp. 2004-2011, 2007.

[28] Y. Song, D. Shan, R. Chen, F. Zhang, and E.-H. Han, "Biodegradable behaviour of AZ31 magnesium alloy in simulated body fluid," Materials Science and Engineering: C, vol. 29, no. 3, pp. 1039-1045, 2009.

[29] G. Wu, Y. Zhao, X. Zhang, J. M. Ibrahim, and P. K. Chu, "Selfprotection against corrosion of aged magnesium alloy in simulated physiological environment," Corrosion Science, vol. 68 , pp. 279-285, 2013. 

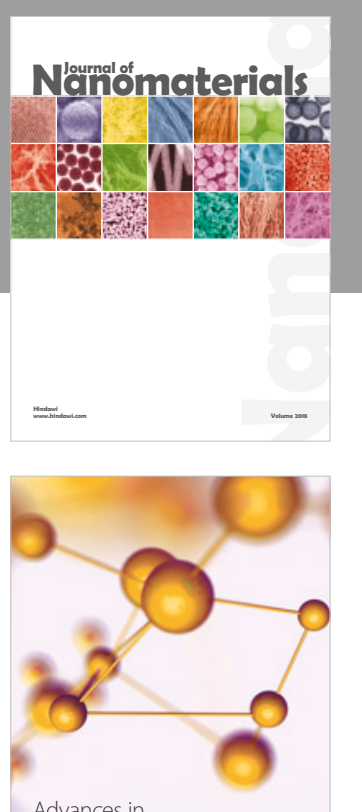

Physical Chemistry
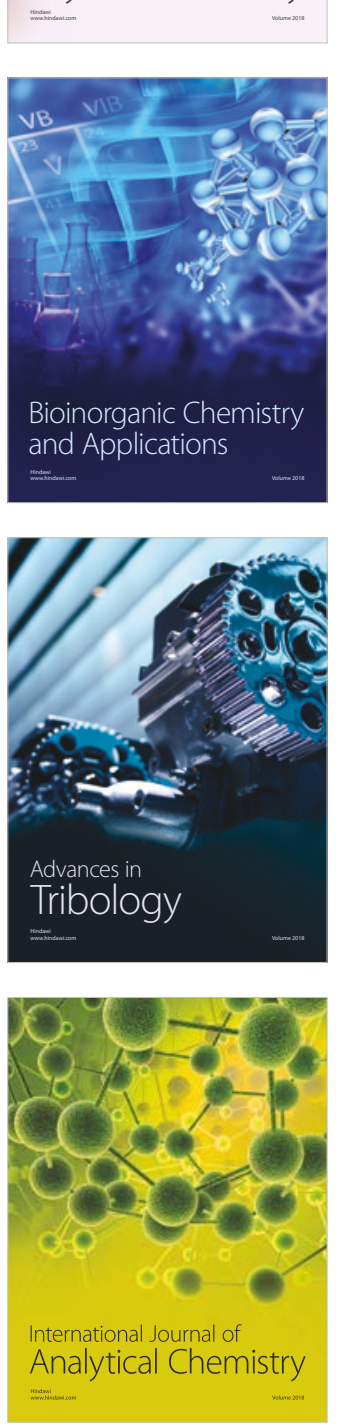

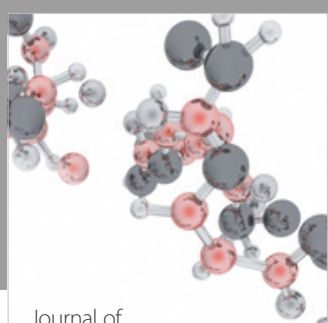

Analytical Methods

in Chemistry

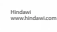

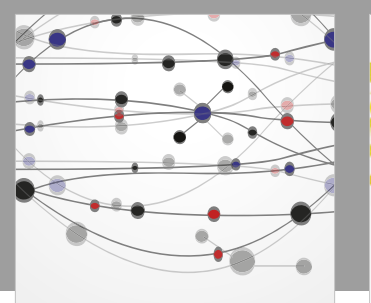

The Scientific World Journal

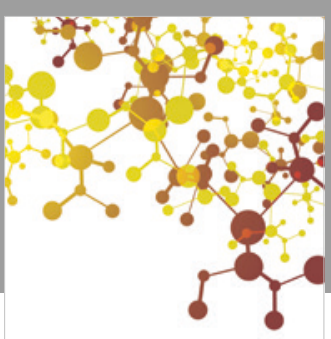

Journal of

Applied Chemistry
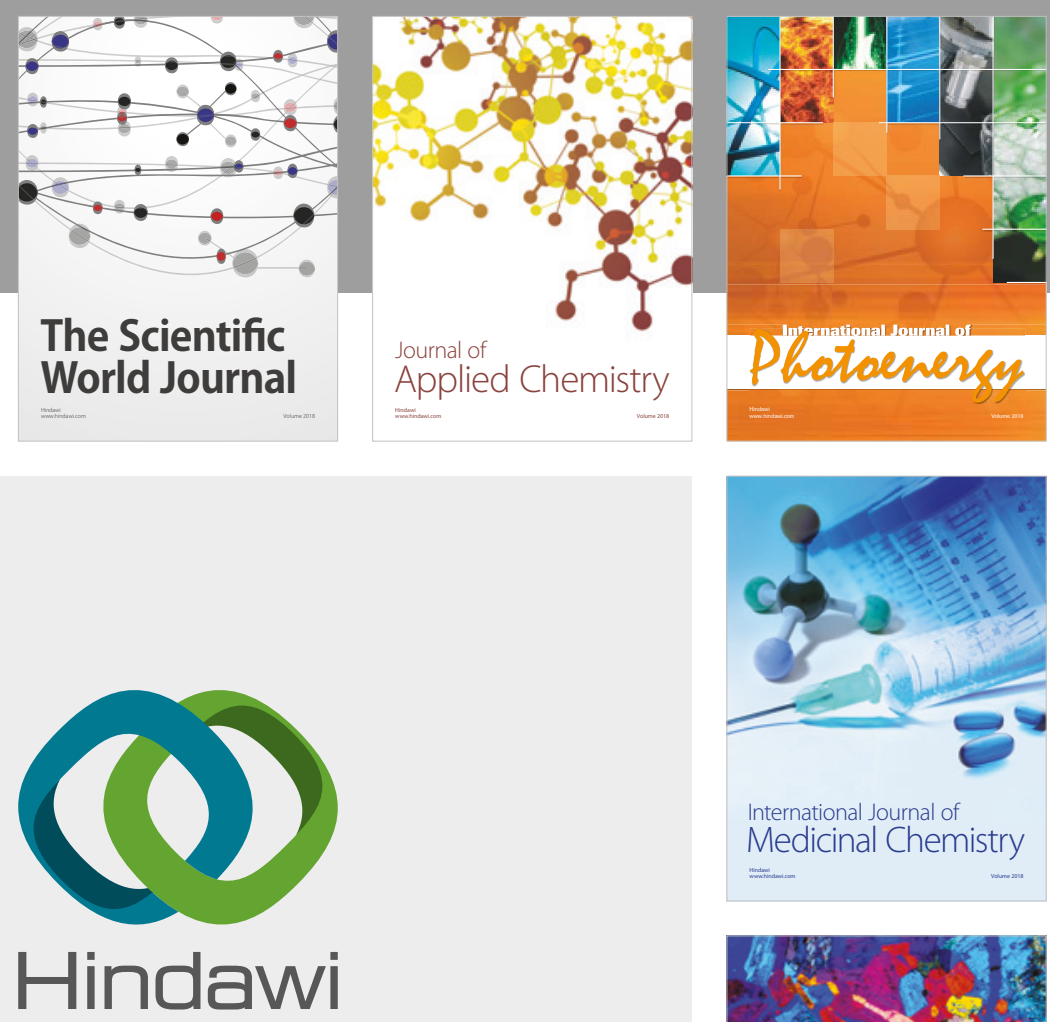

Submit your manuscripts at

www.hindawi.com
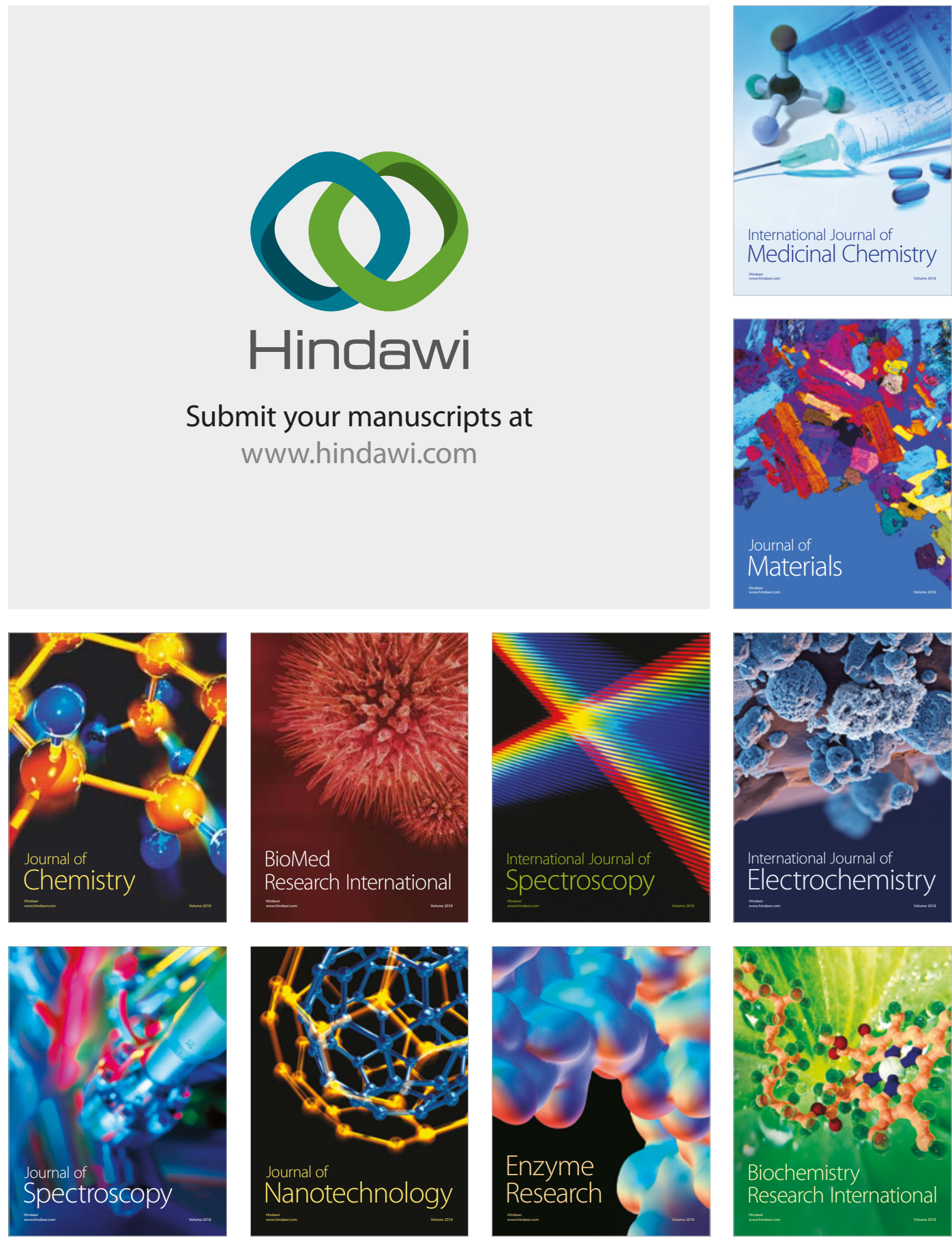
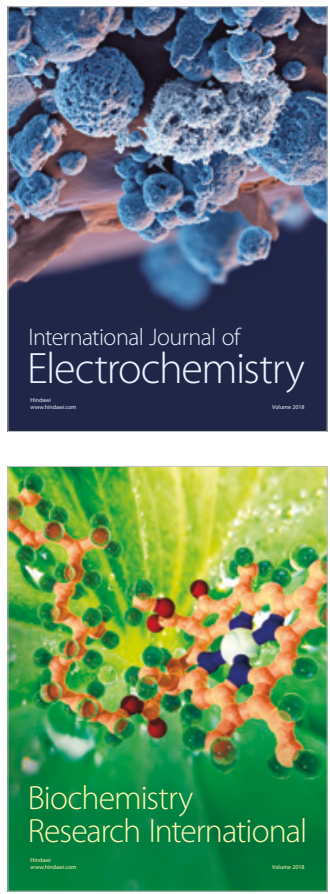